\title{
Amino Acid Substitutions in the Hormone-binding Domain of the Human Androgen Receptor Alter the Stability of the Hormone Receptor Complex
}

\author{
Marco Marcelli, * Sonia Zoppi, * Carol M. Wilson, *‡ James E. Griffin, * and Michael J. McPhaul \\ *Department of Internal Medicine and ${ }^{\ddagger}$ Department of Pharmacology, The University of Texas Southwestern Medical Center at Dallas, \\ Dallas, Texas 75235-8857
}

\begin{abstract}
We have investigated the basis of androgen resistance in seven unrelated individuals with complete testicular feminization or Reifenstein syndrome caused by single amino acid substitutions in the hormone-binding domain of the androgen receptor. Monolayer-binding assays of cultured genital skin fibroblasts demonstrated absent ligand binding, qualitative abnormalities of androgen binding, or a decreased amount of qualitatively normal receptor.

The consequences of these mutations were examined by introducing the mutations by site-directed mutagenesis into the androgen receptor cDNA sequence and expressing the mutant cDNAs in mammalian cells. The effects of the amino acid substitutions on the binding of different androgens and on the capacity of the ligand-bound receptors to activate a reporter gene were investigated. Substantial differences were found in the responses of the mutant androgen receptors to incubation with testosterone, $5 \alpha$-dihydrotestosterone, and mibolerone. In several instances, increased doses of hormone or increased frequency of hormone addition to the incubation medium resulted in normal or near normal activation of a reporter gene by cells expressing the mutant androgen receptors. These studies suggest that the stability of the hormone receptor complex is a major determinant of receptor function in vivo. (J. Clin. Invest. 1994. 94:16421650.) Key words: androgen $\cdot$ receptor $\bullet$ hormone resistance - insensitivity
\end{abstract}

\section{Introduction}

The syndromes caused by mutations in the androgen receptor gene encompass a spectrum of phenotypic abnormalities ranging from phenotypic women with the syndrome of complete testicular feminization to men with minor defects of virilization or infertility. Monolayer-binding assays of $\left[{ }^{3} \mathrm{H}\right]$ dihydrotestosterone binding in genital skin fibroblasts cultured from affected subjects have defined four categories of defective re-

Address correspondence to Michael J. McPhaul, M.D., Department of Internal Medicine, UT Southwestern Medical Center, 5323 Harry Hines Boulevard, Dallas, TX 75235-8857. M. Marcelli's present address is Department of Internal Medicine, Baylor College of Medicine, Houston, TX 77030.

Received for publication 28 March 1994 and in revised form 14 July 1994

J. Clin. Invest.

(c) The American Society for Clinical Investigation, Inc.

0021-9738/94/10/1642/09 \$2.00

Volume 94, October 1994, 1642-1650 ceptors: absent androgen binding, normal androgen binding, qualitative abnormalities of androgen binding, and reduced androgen binding (1). The isolation of cDNAs encoding the androgen receptor and the definition of its genomic structure have allowed the characterization of the molecular defects responsible for androgen resistance in all four categories.

The largest number (approximately two-thirds) of androgen receptor abnormalities characterized to date are caused by mutations that result in amino acid substitutions in the protein. These mutations cause the replacement of amino acid residues in the DNA- or hormone-binding domain of the androgen receptor. In contrast to the other types of androgen receptor defects (gene deletions, termination codons, and abnormalities of mRNA splicing), which nearly always give rise to complete testicular feminization, amino acid substitutions can cause phenotypes that encompass the entire spectrum of androgen resistance.

In the present report, we investigated the basis of androgen resistance of seven patients in whom androgen resistance is caused by amino acid substitutions in the hormone-binding domain. One was characterized by the absent androgen binding, five by qualitative abnormalities of androgen binding, and one by a reduced level of qualitatively normal androgen binding.

\section{Methods}

Cell cultures. Primary cultures of genital skin from patients N-69, Q571 , and Q-851 were established as previously described (2) and maintained in MEM with $10 \%$ FCS and $1 \%$ penicillin and streptomycin. $\mathrm{CHO}$ and CV1 cells were obtained from the American Type Culture Collection (Rockville, MD) and were maintained as previously described (3).

Monolayer-binding analysis. Monolayer-binding analysis in cultured fibroblasts or transfected cells was performed as previously described (4). Briefly, monolayer cultures were incubated with medium containing different concentrations of ${ }^{3} \mathrm{H}$-labeled dihydrotestosterone (DHT) ${ }^{1}$ in the presence or absence of a 500-fold excess of unlabeled ligand. After incubation for $1 \mathrm{~h}$ at $37^{\circ} \mathrm{C}$ the culture was rinsed, harvested, and assayed for protein and tritiated steroid content. Thermolability was assessed by incubating monolayer cultures with saturating concentration of ligand at $37^{\circ} \mathrm{C}$ and $41^{\circ} \mathrm{C}$ for $1 \mathrm{~h}$. A reduction in specific androgen binding at $41^{\circ} \mathrm{C}$ compared to $37^{\circ} \mathrm{C}$ of greater than $40 \%$ is defined as thermolabile. After incubation, the cells were harvested and processed as above (4). The rate of ligand dissociation was examined by incubating parallel cultures with $2 \mathrm{nM}\left[{ }^{3} \mathrm{H}\right]$ mibolerone for $1 \mathrm{~h}$ at $37^{\circ} \mathrm{C}$ in the presence or absence of excess unlabeled mibolerone. At time 0 the medium containing the radioactive ligand was removed and replaced with medium containing $2 \mathrm{nM}$ cold mibolerone, and the incubation was continued for $5 \mathrm{~h}$. The percentage of specific mibolerone binding remaining at hourly intervals was then compared to the level of specific

1. Abbreviation used in this paper: $\mathrm{DHT}$, dihydrotestosterone; $\mathrm{Mb}, \mathrm{mi}-$ bolerone; $\mathrm{T}$, testosterone. 
mibolerone binding in samples to which no competitor steroid had been added (4). The dissociation rate is considered normal if $>60 \%$ of the specific androgen binding remains after $3 \mathrm{~h}$.

Immunoblot analysis. Immunoblot analysis of genital skin fibroblasts and of transfected eukaryotic cells was performed as described elsewhere (5) using polyclonal antipeptide antibodies (U402) directed at the first 21 amino acid residues of the amino terminus of the androgen receptor protein.

Site-directed mutagenesis. The mutations detected in patients Q851, N-69, Q-48, Q-593, Q-691, and R-855 were inserted into an androgen receptor cDNA expression vector as previously described $(6,7)$. Briefly, two oligonucleotides containing the detected mutations and directed $5^{\prime} \rightarrow 3^{\prime}(\mathrm{S})$ or $3^{\prime} \rightarrow 5^{\prime}(\mathrm{AS})$ were synthesized and used with oligonucleotides $\mathrm{MutH}_{3}$ and 710 -Xba to amplify the portion of androgen receptor cDNA located between the internal HindIII site and an XbaI site located just $3^{\prime}$ of the coding sequence. The final product of the reaction, which contains a HindIII restriction endonuclease cleavage site at the $5^{\prime}$ terminus and an $\mathrm{XbaI}$ restriction site at the $3^{\prime}$ terminus was ligated into an expression plasmid driven by the cytomegalovirus promoter. The expression plasmid contains androgen receptor cDNA, from which the region between the internal HindIII site and the XbaI site located $3^{\prime}$ of the coding sequence had been deleted. The insertion of the correct sequence was confirmed by nucleotide sequence analysis of the resulting plasmids.

Cell culture and transfection. The CV1 cells and CHO cells used for transfection studies of mutants and wild-type androgen receptors do not express endogenous androgen receptor. $\mathrm{CHO}$ cells are deficient in androgen metabolizing enzymes while CV1 cells actively metabolize androgen (8).

Transfection experiments were performed by the calcium phosphate precipitation method (9). CV1 cells were transiently transfected with plasmids encoding normal or mutant androgen receptors (200 $\mathrm{ng}$ ), the reporter plasmid MMTV-luciferase $(10 \mu \mathrm{g})$, and a control plasmid, CMV- $\beta$-galactosidase ( $1 \mu \mathrm{g}$ ). After transfection, the cells were incubated in medium containing $5 \%$ charcoal stripped serum and saturating concentrations of DHT ( $2 \mathrm{nM}$ ) for $48 \mathrm{~h}$. After $48 \mathrm{~h}$, the cell cultures were harvested and assayed for $\beta$-galactosidase and luciferase (10) activity. In these experiments, luciferase activity reflects the transcriptional activity of the different androgen receptors, and $\beta$-galactosidase activity is used to correct for the efficiency of transfection.

Experiments examining the transcriptional activity exerted by the normal androgen receptor (CMV3.1) and the 851 mutation (CMV851) in the presence of different ligands were performed by transfecting CV1 cells as described above and by using saturating concentrations of testosterone, DHT, or mibolerone for $48 \mathrm{~h}$ after transfection. Experiments examining the effect of supraphysiologic concentration of DHT on the transcriptional activity exerted by the normal androgen receptor and mutants Q-571 and Q-851 were performed by transient transfection of CV1 cells with the above plasmids and by stimulation for $48 \mathrm{~h}$ after transfection with 2 or $20 \mathrm{nM}$ of DHT.

CHO cells were used in stable transfection experiments to examine the effects of mutations on the ligand-binding properties of the receptor. In these experiments, cDNAs encoding normal or mutant androgen receptors were cotransfected with the plasmid psV2neo (11). After selection with medium containing $400 \mu \mathrm{g} / \mathrm{ml}$ of active $\mathrm{G} 418$ pools of cells ( $\sim 50-200$ independent colonies $)$ were used in monolayer-binding experiments.

\section{Results}

Clinical background and clinical history. The subjects investigated in this study were affected by complete testicular feminization (N-69, Q-571, Q-851, R-855) or Reifenstein syndrome (Q-48, Q-593, Q-691). N-69 and Q-571 are patients of Dr. G. Costin (Los Angeles, CA), and Q-851 is a patient of Dr. M. Harbison (New York, NY). The clinical features and the andro- gen-binding properties in genital skin fibroblast monolayers are summarized in Table I. In two patient samples (Q-571 and Q593) $B_{\max }$ values are somewhat higher than previously reported (12). The values included in Table I reflect the results of more recent binding analyses. The reason for these differences is not clear, but may reflect subtle methodologic changes.

Immunoblot analysis of genital skin fibroblasts. To determine whether absent or reduced levels of specific androgen binding in fibroblast cultures is due to the expression of a defective form of androgen receptor or alteration in the level of androgen receptor expression, the level of androgen receptor protein expression was estimated by immunoblot analysis in cultured genital skin fibroblasts (5) (Fig. 1). Strain N-69 produces immunoreactive androgen receptor protein that is indistinguishable in size or amount from the $110-\mathrm{kD}$ androgen receptor protein doublet produced by control fibroblasts (strain 704, Fig. 1 ). Thus, there is a striking contrast between the results of ligand-binding assays and immunoblot analyses of genital skin fibroblasts of patient $\mathrm{N}-69$. As expected from the monolayerbinding data, fibroblast cultures from patients Q-571 and Q-851 (Fig. 1) also produce immunoreactive $110 \mathrm{kD}$ androgen receptor protein. Similar levels of immunoreactive $110 \mathrm{kD}$ androgen receptor were detected for patients Q-593, Q-691, and R-855 (data not shown).

Sequence analysis of mutant androgen receptors. Southern analysis of genomic DNA from all seven patients indicated that, in each, the coding segments of the androgen receptor gene is present and grossly intact (reference 7 , data not shown). We have reported previously (12) the identification of single nucleotide substitutions in the androgen receptor gene from each patient that result in the replacement of single amino acid residues within the hormone-binding domain of the receptor protein (Table I). Notably, the amino acid substitutions predicted for mutants N-69, Q-571, Q-48, and Q-851 are localized in a cluster of mutations within the amino terminus of the hormone-binding domain, while the substitutions predicted for the Q-593, Q-691, and R-855 mutant receptors are within the carboxy terminus cluster of mutations. The remaining portion of the androgen receptor open-reading frame that was sequenced was identical in each case except for minor differences in the length of the polymorphic glutamine homopolymeric segment comprising amino acids 58-78. The glycine homopolymeric segment (amino acids 448-470) was not sequenced.

Monolayer-binding analysis of stably transfected $\mathrm{CHO}$ cells. The metabolism of androgens is rapid in fibroblasts and in many cell lines. For this reason, studies of the kinetics of ligand association and dissociation usually require the use of substituted, nonmetabolizable androgens. The stable expression of the mutant receptors in CHO cells (which are relatively deficient in steroid-metabolizing enzymes; reference 8) permits comparison of the binding of a variety of steroids to the mutant receptors under conditions in which steroid metabolism is negligible (Table II).

As expected, substantial levels of specific DHT binding were detected in cells expressing the androgen receptors predicted for patients Q-691, Q-851, R-855, Q-593, and Q-48. As expected from the fibroblast binding assays, the receptors predicted for three of these five patients are qualitatively abnormal as demonstrated by analysis of the rate of dissociation of ligand from the receptor.

In agreement with the results of binding assays performed 
Table I. Androgen Receptor Binding Characteristics of Normal and Mutant Fibroblast Strains

\begin{tabular}{|c|c|c|c|c|c|c|}
\hline $\begin{array}{l}\text { Fibroblast } \\
\text { strain }\end{array}$ & Phenotype & $B_{\max }$ & Mutation & Apparent $K_{\mathrm{d}}$ & Thermolabile & $\begin{array}{l}\text { Dissociation } \\
\text { rate }\end{array}$ \\
\hline & & fmol/mg protein & & $n M$ & & \\
\hline 704 & Normal & 36 & None & 0.08 & No (Normal) & Normal \\
\hline N-69 & CTF & $<4$ & W739R & N/A & N/A & N/A \\
\hline Q-571 & CTF & 9 & F762L & ND & ND & Abnormal \\
\hline Q-48 & Reif & 23 & A746D & ND & No & Abnormal \\
\hline Q-851 & CTF & 17 & P764S & 0.2 & No & Abnormal \\
\hline Q-593 & Reif & 14 & $\mathrm{R} 838 \mathrm{H}$ & 1.2 & No & Abnormal \\
\hline Q-691 & Reif & 10 & $\mathrm{R} 838 \mathrm{C}$ & 0.9 & Yes & Normal \\
\hline $\mathrm{R}-855$ & CTF (Reif) & 13 & $\mathrm{R} 853 \mathrm{H}$ & 0.6 & No & Normal \\
\hline
\end{tabular}

The fibroblast strain is shown to the left. 704 was established from a normal control. N, R, and Q denote strains with absent androgen binding, reduced androgen binding, and qualitatively abnormal androgen binding, respectively. Reif denotes Reifenstein phenotype and CTF denotes complete testicular feminization. The mutation reported for patient R-855 (CTF) has also been detected in a fibroblast strain established from a patient with the Reifenstein phenotype (strain 217, reference 12 ). $B_{\max }$ and apparent $K_{\mathrm{d}}$ were measured using $\left[{ }^{3} \mathrm{H}\right] 5 \alpha$-dihydrotestosterone in whole cell monolayerbinding assays (4). Thermolability and measurements of ligand dissociation characteristics were determined as before (4). Because of the sensitivity of the androgen-binding assay, values $\leq 4 \mathrm{fmol} / \mathrm{mg}$ protein have been considered to be androgen-binding negative. The positions of the amino acid substitutions are reported using the amino acid numbering coordinates of Tilley et al. (13).

in the genital skin fibroblast cultures, substantial levels of DHT binding were detected in $\mathrm{CHO}$ cell lines expressing each of the mutant androgen receptors, except for cells expressing the receptor predicted for mutant $\mathrm{N}-69$. In this instance, specific binding could not be detected using labeled testosterone, DHT, or mibolerone, despite the fact that immunoreactive androgen receptor was readily detectable (data not shown). This result suggests that the amino acid replacement predicted for the $\mathrm{N}$ 69 mutant receptor (W739R) results in a major derangement of the hormone-binding pocket that renders the receptor incapable of binding androgen.

In most instances, the levels of androgen binding by the mutant androgen receptors are similar when measured with testosterone, DHT, and mibolerone. This is not true for the pattern of hormone binding observed for the 571 mutant receptor

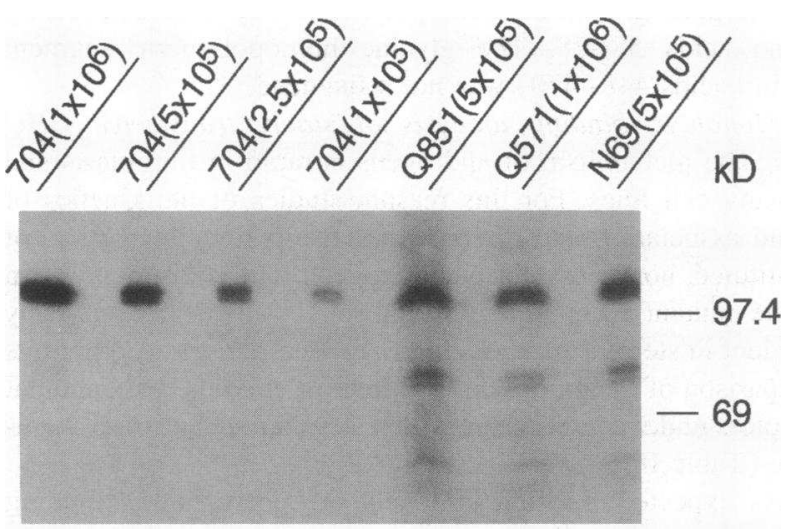

Figure 1. Immunoblot analysis of immunoreactive androgen receptor expression in fibroblasts from normal (704) and mutant (Q-69, Q-571, Q-851) fibroblast strains. Cells were harvested, solubilized, and electrophoresed on a $7.5 \%$ SDS-polyacrylamide gel, transferred to nitrocellulose and probed with an antibody (U402) directed at the amino terminus of the receptor protein (5). The number of cells applied is shown in parentheses.
(F762L). As shown in Table II, the 571 receptor is able to bind $5 \alpha$-DHT and mibolerone but unable to bind testosterone when assayed in whole cell monolayer binding assays. Interestingly, although the 571 mutant androgen receptor can bind mibolerone, this ligand rapidly dissociates from the receptor, raising the possibility that the lack of binding observed using labeled testosterone might be due to extreme instability of the 571 androgen receptor-testosterone complex in the monolayer-binding assay. To address this possibility, we examined the ability of unlabeled androgens (testosterone, DHT, and mibolerone) to compete for the binding of labeled DHT by the 571 androgen receptor. The results of these experiments are shown in Fig. 2. These results indicate that testosterone is able to compete with $\left[{ }^{3} \mathrm{H}\right] \mathrm{DHT}$ for binding to the 571 receptor, albeit less efficiently than is observed for the normal androgen receptor. This suggests that the lack of testosterone binding detected in monolayerbinding assays of the 571 androgen receptor in $\mathrm{CHO}$ cells is largely due to an instability of the 571 mutant androgen receptor-testosterone complex.

Transcriptional activity of the mutant androgen receptors in CVl cells. The transcriptional activity of the mutant androgen receptors was assessed by cotransfecting $\mathrm{CV} 1$ cells with normal or mutant androgen receptors and a reporter plasmid (MMTVluciferase) driven by the MMTV promoter. Following incubation with hormone for $48 \mathrm{~h}$, the cells were assayed for luciferase activity (Table III). The levels of luciferase activity induced in response to androgen differed markedly in cells transfected with the different mutant androgen receptor cDNAs. Using a single addition of a saturating concentration of $5 \alpha$-DHT ( $2 \mathrm{nM})$, the normal androgen receptor stimulated the MMTV-luciferase reporter gene from 76- to 295 -fold in four different experiments. By contrast, under identical assay conditions, the mutant androgen receptors predicted for patients N-69, Q-571, Q-851, and Q-593 were unable to stimulate the reporter gene $(0,1,9$, and $8 \%$, respectively, of the parallel control assays). The other mutant androgen receptors stimulate luciferase activity in response to DHT, ranging from $48 \%$ (mutant Q-855) to $77 \%$ 
Table II. Ligand Binding Properties of Normal and Mutant ARs Stably Expressed in CHO Cells

\begin{tabular}{|c|c|c|c|c|c|c|c|c|c|c|c|}
\hline \multirow[t]{3}{*}{$\begin{array}{c}\text { Expression } \\
\text { plasmid }\end{array}$} & \multirow[t]{3}{*}{ Mutation } & \multirow[t]{3}{*}{ Hormone } & \multirow{3}{*}{$\frac{B_{\max }}{\text { fmollmg protein }}$} & \multirow{3}{*}{$\frac{\text { Apparent } K_{\mathrm{d}}}{n M}$} & \multirow[t]{3}{*}{ Thermolabile } & \multicolumn{6}{|c|}{ Dissociation rate } \\
\hline & & & & & & & & radioact & remain & & \\
\hline & & & & & & $O h$ & $1 \mathrm{~h}$ & $2 h$ & $3 h$ & $4 h$ & $5 h$ \\
\hline \multirow{3}{*}{ CMV3.1 } & None & $\mathbf{T}$ & 34 & 0.29 & & & & & & & \\
\hline & & DHT & 37 & 0.26 & No & & & & & & \\
\hline & & $\mathbf{M b}$ & 20 & 0.09 & & 100 & 92 & 85 & 80 & 70 & ND \\
\hline \multirow[t]{3}{*}{ CMV69 } & W739R & $T$ & 0 & N/A & & & & & & & \\
\hline & & DHT & 0 & N/A & & & & & & & \\
\hline & & $\mathbf{M b}$ & 0 & N/A & & & & & & & \\
\hline \multirow[t]{3}{*}{ CMV571 } & F762L & $\mathbf{T}$ & 0 & N/A & & & & & & & \\
\hline & & DHT & 23 & 0.1 & No & & & & & & \\
\hline & & $\mathbf{M b}$ & 9.1 & 0.17 & & 100 & 7.4 & 0.2 & 1.7 & 1.1 & \\
\hline \multirow[t]{3}{*}{ CMV48 } & A746D & $\mathbf{T}$ & 6 & 0.27 & & & & & & & \\
\hline & & DHT & 40 & 0.6 & No & & & & & & \\
\hline & & $\mathbf{M b}$ & 21 & 0.17 & & 100 & 41 & 10 & 4 & 2 & 1 \\
\hline \multirow[t]{3}{*}{ CMV851 } & P764S & $\mathrm{T}$ & 15 & 0.07 & & & & & & & \\
\hline & & DHT & 26 & 0.15 & No & & & & & & \\
\hline & & $\mathrm{Mb}$ & 14 & 0.06 & & 100 & 60 & 37 & 22 & 12 & 3 \\
\hline \multirow[t]{3}{*}{ CMV593 } & R838H & $\mathrm{T}$ & 11.1 & 0.07 & & & & & & & \\
\hline & & DHT & 21 & 0.08 & No & & & & & & \\
\hline & & $\mathbf{M b}$ & 21 & 0.13 & & 100 & 71 & 58 & 51 & 41 & 38 \\
\hline \multirow[t]{3}{*}{ CMV691 } & R838C & $\mathrm{T}$ & 8.6 & 0.11 & & & & & & & \\
\hline & & DHT & 22 & 0.2 & No & & & & & & \\
\hline & & $\mathrm{Mb}$ & 15 & 0.2 & & 100 & 85 & 73 & 65 & 60 & 50 \\
\hline \multirow[t]{3}{*}{ CMV855 } & R853H & $\mathrm{T}$ & 12 & 0.8 & & & & & & & \\
\hline & & DHT & 24 & 0.1 & No & & & & & & \\
\hline & & $\mathrm{Mb}$ & 26 & 0.08 & & 100 & 78 & 76 & 72 & 61 & 60 \\
\hline
\end{tabular}

Binding assays were performed on pools of G418-resistant cells transfected with the indicated expression plasmids. Thermolability and dissociation rates were measured and classified as described in the text. Thermolability is defined as greater than a $40 \%$ decline in androgen binding when performed at $41^{\circ} \mathrm{C}$ compared to parallel results performed at $37^{\circ} \mathrm{C}$. A dissociation rate is considered normal when greater than $60 \%$ of the specific androgen binding remains at $3 \mathrm{~h}$. N/A, not applicable; $\mathrm{T}$, testosterone; $\mathrm{Mb}$, mibolerone.

(mutant Q-48) of that observed for the normal androgen receptor.

The substantial level of functional activity in functional assays observed for several of the mutants (e.g., patients Q-48, Q-691, and Q-855) prompted us to examine whether a defect in the capacity of less potent androgens such as testosterone might correlate better with the phenotypic abnormalities observed in the patients. As shown in Table III, incubation of cells transfected with a cDNA encoding the normal androgen receptor with a saturating concentration of testosterone induces the MMTV-luciferase reporter gene to a level that is similar to that attained with DHT, in line with previous observations (8). By contrast, only the mutant receptor for patient Q-691 showed comparable levels of activity following stimulation with DHT or testosterone. The differential response to DHT and testosterone stimulation was most pronounced in mutant Q-48 ( 77 vs. $18 \%$ of the activity observed for the normal androgen receptor stimulated with DHT).

Equally striking were the results obtained after stimulation of the transfected cells with the potent androgen mibolerone. In contrast to the results obtained with testosterone and DHT, a substantial induction of luciferase activity was observed for all but one of the mutant receptors $(\mathrm{N}-69)$, including several that would be predicted to be markedly defective in functional assays on the basis of patient phenotype. In fact, stimulation with mibolerone resulted in induction of the luciferase activity by several mutant androgen receptors (e.g., Q-48, Q-851, and R-593) to levels approaching that observed for the normal androgen receptor assayed in parallel. Only the N-69 mutant was unable to respond in the functional assay, and this receptor was also unable to bind testosterone, DHT, or mibolerone in monolayer-binding assays (Table I).

The activation of the MMTV-luciferase reporter by the mutant receptors is partially restored by increased concentrations or frequent additions of dihydrotestosterone. Since the mutant receptor produced in Q-851 fibroblasts shows an increased rate of ligand dissociation, we investigated whether a partial or complete restoration of transcriptional activity would result from incubating CV1 cells expressing the Q-851 androgen receptor with a supraphysiologic concentration of ligand $(20 \mathrm{nM})$ or by increasing the frequency of hormone addition. As shown in Table IV, CV1 cells transfected with the normal androgen receptor (CMV3.1) showed similar levels of reporter gene activation when incubated with 2 or 20 nM DHT. Furthermore, alterations in the frequency of hormone addition (every $12 \mathrm{~h}$ for 48 $\mathrm{h}$ or once in a 48 -h period) did not lead to remarkable changes 


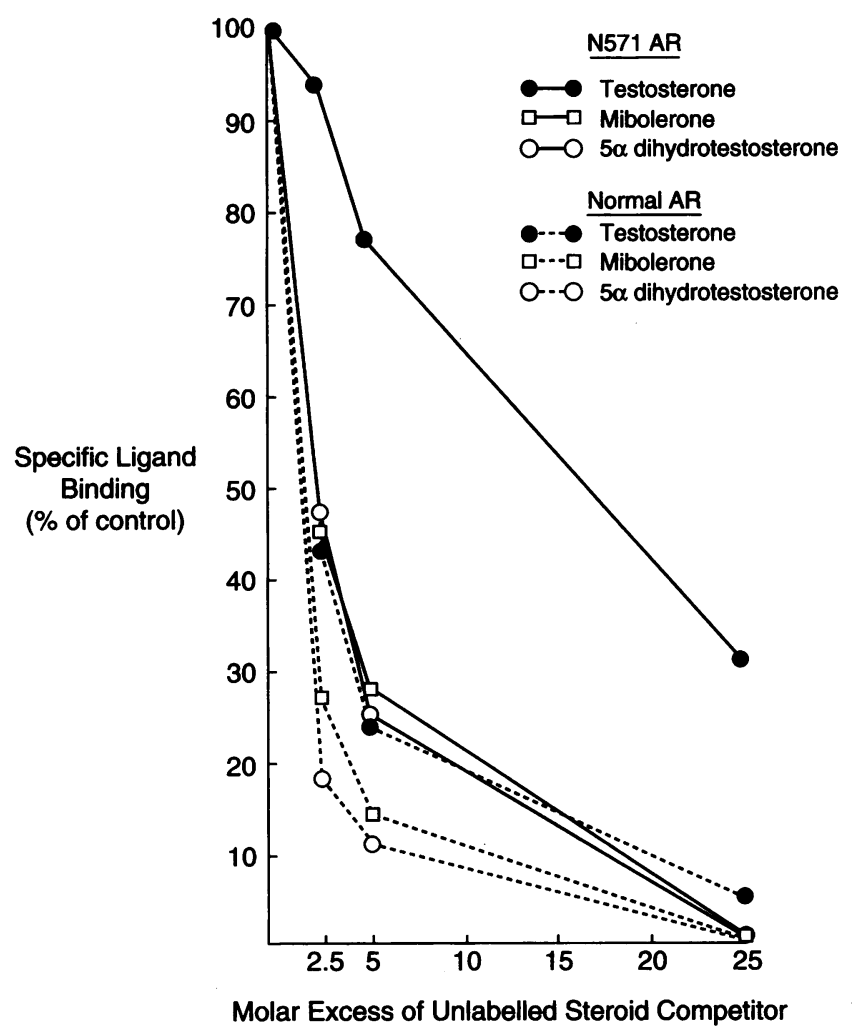

Figure 2. Competition of $\left[{ }^{3} \mathrm{H}\right] 5 \alpha$-DHT binding by testosterone, $5 \alpha$ DHT, and mibolerone. Monolayer cultures of CHO cells stably expressing the normal or $\mathrm{N}-69$ androgen receptor were incubated with $\left[{ }^{3} \mathrm{H}\right] 5 \alpha$ DHT alone or in combination with the indicated excess of unlabeled steroid. The data is expressed as percent of specific binding observed in the absence of unlabeled steroid competitor $(114 \mathrm{fmol} / \mathrm{mg}$ protein for normal androgen receptor and $11 \mathrm{fmol} / \mathrm{mg}$ protein for the Q-571 androgen receptor).

in the level of luciferase activity in cells transfected with the normal androgen receptor. Similar results were obtained when the cells were incubated with mibolerone.

By contrast, the concentration of hormone and the frequency of hormone addition had a dramatic effect on the androgendependent induction of luciferase activity in cells transfected with the 851 mutant cDNA. Incubation with $20 \mathrm{nM}$ DHT for $48 \mathrm{~h}$ led to a 10-fold increase in receptor function (from 2.9 to $28 \%$ of the activity observed for the normal control). A similar effect was observed when the hormone concentration remained $2 \mathrm{nM}$, but the frequency of hormone addition was changed to every $12 \mathrm{~h}$. This effect of hormone concentration and addition protocol was not observed when the nonmetabolizable androgen mibolerone was employed, as similar levels of reporter gene induction were observed for mibolerone using 2 - or $20-\mathrm{nM}$ concentrations, added once or every $12 \mathrm{~h}$. Increases in the level of luciferase reporter gene activity were not observed when these manipulations were applied to cells transfected with the N-69 androgen receptor cDNA.

These results suggested that a shortened half-life of the hormone receptor complexes might underlie the abnormalities of the mutant receptors and might account for the changes in mutant androgen receptor function in response to enhanced hor- mone concentrations, increased frequency of hormone addition, and incubation with nonmetabolizable androgen (mibolerone).

This inference is supported by the results tabulated in Table $\mathrm{V}$, which summarizes the functional activity of the normal androgen receptor and two mutant androgen receptors in response to single or multiple additions (upper panel) 1-h pulses (lower panel) of saturating concentrations of $5 \alpha$-DHT or mibolerone. Under these circumstances, the alterations of mutant androgen receptor function become even more apparent. Nearly $50 \%$ of maximal reporter gene activation can be achieved for the normal receptor following four 1-h pulses of hormone incubation over a 48-h period. In contrast, a similar response to additional pulses of hormone was not observed with the 851 and 855 mutant androgen receptors, suggesting that the stability or duration of action of the mutant hormone receptor complexes formed during these incubations is diminished. Even short pulses of mibolerone were able to induce higher levels of reporter gene activation than incubation with pulses of DHT. This observation is true for both the normal and mutant receptors.

These observations regarding the stimulation of the normal and mutant receptors suggest that the mutant 855 hormone receptor complex is less stable. Notably, when measured during the course of ligand dissociation rate measurements, the stability of the mutant $\mathbf{8 5 5}$ hormone receptor complexes (measured as the quantity of specific hormone receptor complexes remaining at each time point in the absence of unlabeled competitor) was not discernibly different from that measured for the normal receptor using $\left[{ }^{3} \mathrm{H}\right]$ mibolerone (Table II) or $\left[{ }^{3} \mathrm{H}\right] 5 \alpha$-dihydrotestosterone (data not shown) as ligand.

\section{Discussion}

In the subjects examined to date, amino acid substitutions in the hormone-binding domain of the androgen receptor are the most common mutations causing androgen resistance and have been detected in individuals with a variety of phenotypes, including complete testicular feminization and Reifenstein syndrome. How these diverse ligand-binding domain mutations cause the different androgen resistant phenotypes has not been determined.

The current report attempts to address this issue. The seven subjects reported in these studies were chosen to encompass a range of abnormalities of androgen binding in genital skin fibroblast cultures caused by amino acid substitutions in the hormone-binding domain of the androgen receptor. Furthermore, the mutations analyzed were chosen to be representative of substitutions within the two regions most frequently affected by amino acid substitutions within the hormone-binding domain.

The results of these studies permit two types of conclusions to be drawn. The first pertains to the relationship between the nature of the amino acid substitutions in the hormone-binding domain of the androgen receptor and observed effects of ligand binding. The second is more general and explores the physiologic ramifications of these observations. Of the mutant receptors examined in this study, the receptor predicted for patient $\mathrm{N}-69$ (W739R) is the most abnormal. This receptor protein does not bind testosterone, DHT, or mibolerone and is inactive in functional studies. These findings indicate that the alteration of the structure of the hormone-binding domain caused by the W739R amino acid substitution is such that the receptor is completely unable to bind androgen. This suggests that the re- 
Table III. Transcriptional Activation Capacities of Normal and Mutant Androgen Receptors in CVI Cells

\begin{tabular}{|c|c|c|c|c|c|c|c|}
\hline $\begin{array}{l}\text { Expression } \\
\text { plasmid }\end{array}$ & Mutation & Hormone & Exp 1 & Exp 2 & Exp 3 & Exp 4 & Average \\
\hline \multirow[t]{3}{*}{ CMV3.1 } & None & $T$ & 71 & 87 & 80 & & 79 \\
\hline & & DHT & 100 & 100 & 100 & 100 & 100 \\
\hline & & $\mathbf{M b}$ & 43 & 85 & 72 & 50 & 62 \\
\hline \multirow[t]{3}{*}{ CMV69 } & W739R & $T$ & 0 & & & & 0 \\
\hline & & DHT & 0 & & & & 0 \\
\hline & & $\mathbf{M b}$ & 0 & & & & 0 \\
\hline \multirow[t]{3}{*}{ CMV571 } & F762L & $T$ & 0 & 0.5 & & & 0.25 \\
\hline & & DHT & 1.7 & 0.5 & & & 1.1 \\
\hline & & $\mathbf{M b}$ & 36 & 19 & & & 28 \\
\hline \multirow[t]{3}{*}{ CMV48 } & A746D & $\mathbf{T}$ & 7.5 & & 28 & & 18 \\
\hline & & DHT & 58 & & 96 & & 77 \\
\hline & & $\mathbf{M b}$ & 94 & & 84 & & 89 \\
\hline \multirow[t]{3}{*}{ CMV851 } & F764S & $\mathrm{T}$ & 2.5 & 2.9 & & & 2.7 \\
\hline & & DHT & 5.9 & 2.0 & & 19 & 9 \\
\hline & & $\mathbf{M b}$ & 102 & 98 & & 160 & 120 \\
\hline \multirow[t]{3}{*}{ CMV593 } & R838H & $\mathrm{T}$ & 3.8 & 8.8 & & & 6.3 \\
\hline & & DHT & 8.6 & 7.1 & & & 7.8 \\
\hline & & $\mathbf{M b}$ & 49 & 74 & & & 62 \\
\hline \multirow[t]{3}{*}{ CMV691 } & R838C & $T$ & 95 & 31 & 75 & & 67 \\
\hline & & DHT & 135 & 13 & 87 & & 67 \\
\hline & & $\mathbf{M b}$ & 171 & 26 & 105 & & 101 \\
\hline \multirow[t]{3}{*}{ CMV855 } & R853H & $\mathrm{T}$ & 15 & & 24 & & 20 \\
\hline & & DHT & 42 & & 54 & & 48 \\
\hline & & $\mathbf{M b}$ & 140 & & 105 & & 123 \\
\hline
\end{tabular}

The results of four separate experiments are presented. For each experiment, cells were transfected, stimulated, and assayed in parallel. Each value presented for each experiment is derived from the mean of three separate transfections assayed in the absence and presence of hormone. For the purposes of comparison between experiments, the values of luciferase activity in each experiment (expressed as fold-induction observed) have been normalized relative to the induction of luciferase activity measured for the cells transfected with the normal androgen receptor and assayed $48 \mathrm{~h}$ following a single addition of $5 \alpha$-DHT. The fold-induction observed for the stimulation of the normal androgen receptor by $5 \alpha$-DHT was 120 -, 295-, 76-, and 64-fold in experiments $1,2,3$, and 4, respectively. The concentrations of androgen used were $2 \mathrm{nM}$ mibolerone (Mb), $2 \mathrm{nM} 5 \alpha-$ dihydrotestosterone (DHT), and $4 \mathrm{nM}$ testosterone (T). Finasteride $(0.1 \mu \mathrm{M})$ was included in all incubations.

placement of the hydrophobic tryptophan at residue 739 by a charged residue alters the hormone-binding domain such that specific binding of ligand is not possible.

In subject Q-571 (F762L), detectable androgen binding is present when the assay is performed at physiologic temperature in stably transfected CHO cells. This mutant androgen receptor is qualitatively abnormal, with rapid dissociation of mibolerone from the receptor. Interestingly, this mutant receptor also demonstrates ligand selectivity: in monolayer-binding assays it binds DHT and mibolerone but not testosterone. These findings suggest that the phenylalanine residue normally present at amino acid 762 is important for the stable binding of androgen. The ligand selectivity of the 571 mutant receptor suggests that this residue may interact with specific structural features of the steroid A ring, as the A-ring conformations of 19-nortestosterone steroids are known to resemble the A-ring conformations of $5 \alpha$-reduced testosterone and its derivatives $(14,15)$. This selectivity is also evident in functional studies: the F762L mutant receptor is not activated by single additions of testosterone or DHT but is activated by mibolerone to a level nearly half of normal.

When stably expressed in CHO cells, the mutant androgen receptor predicted for patient Q-851 (P764S) behaves in a fash- ion similar to the androgen binding detected in cultured genital skin fibroblasts from this subject: the receptor displays normal affinity for androgen, and the only abnormality of binding detected is the rapid dissociation of ligand. It is interesting that a single amino acid replacement results in the phenotype of complete testicular feminization when the abnormally rapid dissociation of ligand from the receptor is the only receptor defect detected in fibroblasts or transfected CHO cells. Despite these subtle alterations of ligand binding, a substantial defect in receptor function is evident when the Q-851 receptor is analyzed in CV1 cells following stimulation with single doses of testosterone or DHT. Consistent with a defect of hormone receptor stability, the functional defect is partially or completely corrected after incubation with a saturating concentration of mibolerone or with repeated additions of DHT.

The androgen receptor predicted for Q-48 also displays an increased rate of ligand dissociation when assayed in fibroblast cultures or in transfected CHO cells. The mutation (A746D) is localized to a position 18 amino acids from the amino acid substitution responsible for the rapid ligand dissociation observed for patient Q-851 (P764S). The Q-571 mutation contains an amino acid replacement in this same region of the androgen receptor (F762L) and also demonstrates a rapid dissociation 
Table IV. Activation of Normal and Mutant Androgen Receptors in CV1 Cells by Varying Concentrations of Androgen

\begin{tabular}{|c|c|c|c|c|c|c|}
\hline $\begin{array}{l}\text { Expression } \\
\text { plasmid }\end{array}$ & Mutation & Hormone & Concentration & $\begin{array}{l}\text { Number of } \\
\text { additions }\end{array}$ & $\begin{array}{c}\text { Fold } \\
\text { induction }\end{array}$ & $\begin{array}{l}\text { Percent } \\
\text { control }\end{array}$ \\
\hline \multirow[t]{8}{*}{ CMV3.1 } & None & DHT & 2 & 1 & 63 & 53 \\
\hline & & & 2 & 4 & 120 & 100 \\
\hline & & & 20 & 1 & 147 & 122 \\
\hline & & & 20 & 4 & 78 & 65 \\
\hline & & $\mathbf{M b}$ & 2 & 1 & 66 & 55 \\
\hline & & & 2 & 4 & 60 & 50 \\
\hline & & & 20 & 1 & 100 & 83 \\
\hline & & & 20 & 4 & 102 & 85 \\
\hline \multirow[t]{8}{*}{ CMV851 } & P764S & DHT & 2 & 1 & 3.5 & 2.9 \\
\hline & & & 2 & 4 & 40 & 33 \\
\hline & & & 20 & 1 & 33 & 28 \\
\hline & & & 20 & 4 & 143 & 118 \\
\hline & & $\mathbf{M b}$ & 2 & 1 & 53 & 44 \\
\hline & & & 2 & 4 & 66 & 55 \\
\hline & & & 20 & 1 & 73 & 61 \\
\hline & & & 20 & 4 & 59 & 49 \\
\hline \multirow[t]{8}{*}{ CMV69 } & W739R & DHT & 2 & 1 & 1 & N/A \\
\hline & & & 2 & 4 & 1 & N/A \\
\hline & & & 20 & 1 & 1 & N/A \\
\hline & & & 20 & 4 & 1 & N/A \\
\hline & & $\mathbf{M b}$ & 2 & 1 & 1 & N/A \\
\hline & & & 2 & 4 & 1 & N/A \\
\hline & & & 20 & 1 & 1 & N/A \\
\hline & & & 20 & 4 & 1 & N/A \\
\hline
\end{tabular}

Cell cultures were transfected with the indicated cDNA, MMTV-luciferase and $\beta$-galactosidase plasmid as indicated in Methods. All incubations with hormone were for a total of $48 \mathrm{~h}$ before harvesting for measurements of luciferase and $\beta$-galactosidase activity. Medium was changed every $12 \mathrm{~h}$ in those cultures with multiple medium changes. Fold-induction represents the level of stimulated luciferase activity (corrected for $\beta$ galactosidase activity) compared to parallel cultures not incubated with hormone. Percent control is expressed as a percentage of the induction observed compared to the induction detected for the normal receptor incubated with 4 additions of $2 \mathrm{nM} \mathrm{DHT}$. Mb, mibolerone; N/A, not applicable.

rate when expressed in $\mathrm{CHO}$ cells (Table II). These observations are of interest when considered in the context of two other patients with androgen resistance in whom binding studies identified an increased rate of ligand dissociation. The subject described by Grino et al. (4) had an amino acid replacement at amino acid residue 761 (Y761S) that was accentuated by an alteration within the amino terminus (3). The subject described by Ris-Stalpers et al. (16) had a mutation at amino acid residue 686 (N686). Taken together, these findings suggest that although more than one region of the androgen receptor hormonebinding domain may be important for the stable interaction of the receptor with the ligand, the segment between residues 746 and 764 may be particularly critical. The data suggest that accelerated dissociation of ligand may be more frequently observed with amino acid substitutions within the amino terminal segments of the hormone-binding domain.

The analysis of Q-593 and Q-691 provide an interesting contrast. Both are the result of amino acid replacements of residue 838 with residues that differ in their chemical properties: the amino acid replacement in 593 is relatively conservative $(R \rightarrow H)$, while that in 691 is not $(R \rightarrow C)$. Despite this substantial difference, these mutant receptors bind ligand almost normally when expressed in $\mathrm{CHO}$ cells, suggesting that these amino acid residues affect receptor function in a fashion not reflected in assays of hormone binding. Instead, alterations of these residues may impair the capacity of the receptor to assume (or maintain) a conformation necessary for full receptor function, perhaps by altering the capacity of the receptor to interact with other components of the transcription apparatus.

Many of the same considerations also apply to the mutant androgen receptor predicted for $\mathrm{R}-855$ ( $\mathrm{R} 853 \mathrm{H})$, as replacement of this charged residue with the conservative charge $(\mathrm{R} \rightarrow \mathrm{H})$ results in little change in the binding of DHT by the receptor in genital skin fibroblasts (Table II). Nevertheless, the R853H amino acid substitution impairs receptor function in transfection assays, particularly following incubation with a single dose of testosterone. An intriguing aspect of these studies is that, in cotransfection assays, this mutant receptor responds to changes in hormone concentration and dosing in a fashion that is similar to a mutant with a clearcut acceleration of ligand dissociation (Q-851; P864S; see Table V). These observations suggest that the stability of the functional hormone receptor complex of the 855 mutant AR is altered by the $\mathrm{R} 853 \mathrm{H}$ amino acid substitution in a manner that is not measured by standard hormone-binding assays. Whether this reflects an effect on the conformation of the hormone-binding domain or the disruption of the interaction of this portion of the androgen receptor with other proteins is not known. It is also not known whether these 
Table V. The Effect of Alterations in Hormone, Hormone Dosing, and Concentration on the Transcriptional Activation Capacities of Normal and Mutant Androgen Receptors in CVI Cells

\begin{tabular}{|c|c|c|c|c|c|}
\hline Hormone & Concentration & Addition & Normal & 851 (P764S) & 855 (R853H) \\
\hline DHT & 2 & $1 \times$ & $115(36 \%)$ & $(1.3 \%)$ & $4.5(1.4 \%)$ \\
\hline DHT & 2 & $4 \times$ & $316(100 \%)$ & $114 \quad(36 \%)$ & $140 \quad(44 \%)$ \\
\hline $\mathbf{M b}$ & 2 & $1 \times$ & $202(64 \%)$ & $160 \quad(51 \%)$ & $159 \quad(50 \%)$ \\
\hline $\mathrm{Mb}$ & 2 & $4 \times$ & $319(101 \%)$ & $245 \quad(78 \%)$ & $252 \quad(80 \%)$ \\
\hline DHT & 2 & $1 \mathrm{P}$ & $27(8.6 \%)$ & $1.3(0.4 \%)$ & 1 \\
\hline DHT & 2 & $4 \mathrm{P}$ & $142(45 \%)$ & $18.5(5.9 \%)$ & $49.5(15.7 \%)$ \\
\hline $\mathbf{M b}$ & 2 & $1 P$ & $198(63 \%)$ & $130 \quad(41.2 \%)$ & $159 \quad(50 \%)$ \\
\hline $\mathrm{Mb}$ & 2 & $4 \mathrm{P}$ & $290(92 \%)$ & $116 \quad(37 \%)$ & $(53 \%)$ \\
\hline
\end{tabular}

The results of two separate experiments are tabulated. In each experiment, for each manipulation triplicate samples were analyzed in the presence and absence of hormone. For the purposes of presentation, the corrected luciferase derived from each treatment category from the two experiments were added together. Fold-induction refers to the level of luciferase activity detected after incubation with hormone compared to parallel samples assayed following incubation with no hormone. The percentages shown in parentheses are the activities of the mutant androgen receptors compared to the level of luciferase activity detected in cells transfected with the normal human androgen receptor incubated with four additions of $2 \mathrm{nM} 5 \alpha$-DHT over a $48 \mathrm{~h}$ period (one addition every $12 \mathrm{~h}$ ). $1 \times$ and $4 \times$ refer to schedules of incubation that utilize a single $(1 \times)$ or multiple $(4 \times)$ additions of hormone ( $4 \times$ refers to four medium changes at $12 \mathrm{~h}$ intervals). $1 \mathrm{P}$ and $4 \mathrm{P}$ are analogous notations but refer to single or multiple pulses ( $1 \mathrm{~h}$ duration) of hormone. In all instances, the cultures were assayed $48 \mathrm{~h}$ after the initial hormone incubation.

findings are related to the detection of this same amino acid substitution in an unrelated subject with the Reifenstein phenotype (12).

In addition to inferences regarding the structure-function organization of the hormone-binding domain of the human androgen receptor, our results have important physiologic implications. First, these findings suggest that the defects underlying the altered function of most of these mutant receptors can be traced to an instability of the hormone receptor complex. Thus, circumstances that alter the steady state concentration of hormone available for receptor binding will alter androgen receptor function. Conditions that increased the availability of metabolizable androgens to the receptor (increased concentration or increased frequency of addition) or the use of nonmetabolizable analogues resulted in increased receptor function in all of the mutant receptors that were capable of binding hormone. In physiologic terms, these findings suggest that genetic differences or pharmacologic manipulations that affect the steady state level of hormone available to complex with the receptor will affect the function of mutant androgen receptors. From a clinical perspective, these observations would suggest that a large proportion of patients with amino acid substitutions in the hormonebinding domain of the androgen receptor would show a demonstrable effect following the administration of pharmacologic doses of natural or synthetic androgens. Interestingly, this inference is in keeping with the results of androgen administration to a patient with Reifenstein phenotype later shown to harbor an amino acid substitution in the hormone-binding domain (4).

Second, although the amino acid substitutions that we have studied are localized within both of the two segments in which androgen receptor hormone-binding domains most frequently cluster, mutations in both of these regions of the receptor show similar patterns in cotransfection assays. This conclusion must be tempered, however, by the small number of substitution mutants that we have studied, particularly within the carboxy terminal group of mutations.
Finally, the relationship between the genetic mutation identified in the androgen receptor gene and the phenotype observed in the patient is certain to be complex. At a minimum, attempts to explore this relationship must examine the changes in the level of androgen receptor expression and the residual function of the receptor caused by the androgen receptor mutation. In this respect, mutant androgen receptors that completely lack the ability to activate androgen-responsive reporter genes are associated with complete testicular feminization, but the partial forms of androgen resistance, such as Reifenstein syndrome, are less well understood. Our study suggests that the results of such experiments may in large part be dependent on the types of assays that are employed to assess the activity of the mutant androgen receptors in transfected cells. In the current study, we show that if a potent nonmetabolizable androgen such as mibolerone is used, a relationship between receptor function and phenotype is difficult to discern. By contrast, if single additions of physiologic ligands are employed instead (testosterone or DHT), the pattern of activity observed appears to have a more direct relationship to phenotype, although this relationship is not precise (see, for example, the results obtained in functional studies of the mutant androgen receptor predicted for patient R-691).

\section{Acknowledgments}

We are indebted to Michele A. Herbst, Elsa Yang, and Diane Rae Allman for technical support, and to Brenda H. Hennis and Christy K. Gonzales for secretarial and editorial assistance. Our thanks to Dr Kevin J. Petty and Dr. Jean D. Wilson for careful perusal of this manuscript.

This work was supported by National Institutes of Health grant DK03892, the Robert A. Welch Foundation (I-1090), and a grant from the Perot Family Foundation. M. Marcelli was supported by a grant awarded by the Endocrine Fellows Foundation.

\section{References}

1. Griffin, J. E., and J. D. Wilson. 1989. The androgen resistance syndromes: $5 \alpha$-reductase deficiency, testicular feminization, and related syndromes. In The 
Metabolic Basis of Inherited Disease. C. R. Scriver, A. L. Beaudet, W. S. Sly, and D. Valle, editors. McGraw-Hill Inc., New York. 1919-1944.

2. Griffin, J. E., and J. L. Durrant. 1982. Qualitative receptor defects in families with androgen resistance: failure of stabilization of the fibroblast cytosol androgen receptor. J. Clin. Endocrinol. \& Metab. 55:465-474.

3. McPhaul, M. J., M. Marcelli, W. D. Tilley, J. E. Griffin, R. F. IsidroGutierrez, and J. D. Wilson. 1991. Molecular basis of androgen resistance in a family with a qualitative abnormality of the androgen receptor and responsive to high-dose androgen therapy. J. Clin. Invest. 87:1413-1421.

4. Grino, P. B., R. F. Isidro-Gutierrez, J. E. Griffin, and J. D. Wilson. 1989. Androgen resistance associated with a qualitative abnormality of the androgen receptor and responsive to high dose androgen therapy. J. Clin. Endocrinol. \& Metab. 68:578-584.

5. Wilson, C. M., J. E. Griffin, J. D. Wilson, M. Marcelli, S. Zoppi, and M. J. McPhaul. 1992. Immunoreactive androgen receptor expression in patients with androgen resistance. J. Clin. Endocrinol. \& Metab. 75:1474-1478.

6. Marcelli, M., W. D. Tilley, C. M. Wilson, J. D. Wilson, J. E. Griffin, and M. J. McPhaul. 1990. A single nucleotide substitution introduces a premature termination codon into the androgen receptor gene of a patient with receptornegative androgen resistance. J. Clin. Invest. 85:1522-1528.

7. Marcelli, M., W. D. Tilley, C. M. Wilson, J. E. Griffin, J. D. Wilson, and M. J. McPhaul. 1990. Definition of the human androgen receptor gene structure permits the identification of mutations that cause androgen resistance: premature termination of the receptor protein at amino acid residue 588 causes complete androgen resistance. Mol. Endocrinol. 4:1105-1116.

8. Deslypere, J.-P., M. Young, J. D. Wilson, and M. J. McPhaul. 1992. Testosterone and $5 \alpha$-dihydrotestosterone interact differently with the androgen receptor to enhance transcription of the MMTV-CAT reporter gene. Mol. Cell. Endocrinol. $88: 15-22$

9. Frost, E., and J. Williams. 1978. Mapping temperature sensitive and hostrange mutations of adenovirus type 5 by marker rescue. Virology. 91:39-50.

10. deWet, J. R., K. V. Wood, M. deLuca, D. R. Helinski, and S. Subramani. 1987. Firefly luciferase gene: structure and expression in mammalian cells. Mol. Cell. Biol. 7:725-737.

11. Southern, P. J., and P. Berg. 1982. Transformation of mammalian cells to antibiotic resistance with a bacterial gene under control of the SV40 early region promoter. J. Mol. Appl. Genet. 1:327-341.

12. McPhaul, M. J., M. Marcelli, S. Zoppi, C. M. Wilson, J. E. Griffin, and J. D. Wilson. 1992. Mutations in the ligand-binding domain of the androgen receptor gene cluster in two regions of the gene. J. Clin. Invest. 90:2097-2101.

13. Tilley, W. D., M. Marcelli, J. D. Wilson, and M. J. McPhaul. 1989. Characterization and expression of a cDNA encoding the human androgen receptor. Proc. Natl. Acad. Sci. USA. 86:327-331.

14. Liao, S., T. Liang, S. Fang, E. Castaneda, and T.-C. Shao. 1973. Steroid structure and androgenic activity. J. Biol. Chem. 248:6154-6162.

15. Saartok, T., E. Dahlberg, and J.-A. Gustafson. 1984. Relative binding affinity of anabolic-androgenic steroids: comparison of the binding to the androgen receptors in skeletal muscle and in prostate, as well as to sex hormone-binding globulin. Endocrinology. 114:2100-2106.

16. Ris-Stalpers, C., M. A. Trifiro, G. G. J. M. Kuiper, G. Jenster, G. Romalo, T. Sai, H. C. J. van Rooij, M. Kaufman, R. L. Rosenfield, S. Liao, et al. 1991. Substitution of aspartic acid- 686 by histidine or asparagine in the human androgen receptor leads to a functionally inactive protein with altered hormone-binding domain characteristics. Mol. Endocrinol. 5:1562-1569. 